\title{
Deprescribing in older people
}

\author{
Michelle Liacos \\ Pharmacist ${ }^{\top}$ \\ Amy Theresa Page \\ Pharmacist $t^{1,2,3}$ \\ Christopher Etherton-Beer \\ Associate professor ${ }^{2}$ \\ Geriatrician and Clinical \\ pharmacologist ${ }^{4}$ \\ ${ }^{1}$ Pharmacy Department, \\ Alfred Health, Melbourne \\ ${ }^{2}$ WA Centre for Health \\ and Ageing, University of \\ Western Australia, Crawley, \\ WA \\ ${ }^{3}$ Centre for Medicine \\ Use and Safety, Monash \\ University, Melbourne \\ ${ }^{4}$ Royal Perth Hospital, Perth
}

\section{Keywords}

aged, deprescribing, drug withdrawal symptoms, falls, polypharmacy

Aust Prescr 2020;43:114-20 https://doi.org/10.18773/ austprescr.2020.033

\section{SUMMARY}

Deprescribing is the process of discontinuing drugs that are either potentially harmful or no longer required.

It can be achieved in older people and may be associated with improved health outcomes without long-term adverse effects.

The risk of drug withdrawal effects can often be mitigated by carefully monitoring and gradually tapering the dose.

Deprescribing should ideally be a shared decision-making process between the patient and the prescriber.

\section{Introduction}

Why deprescribe? Older people living with multiple chronic diseases often have a high risk of adverse health events which can be modified by medicines. For these people, the quality use of medicines includes starting new drugs, adjusting doses and discontinuing those that are no longer beneficial. Despite the great potential benefit they can derive from medicines, these patients are at high risk of experiencing medicine-related harm. Using more drugs than is clinically indicated can increase this risk.

Polypharmacy, defined as the concomitant use of five or more medicines, ${ }^{1}$ is associated with an increased risk of adverse outcomes such as hospital admissions, falls and premature mortality., It is also expensive for patients. The number of older Australians affected has increased by over $50 \%$ since 2006 to nearly one million. ${ }^{3}$ This rising prevalence and the associated concerns about poorer health outcomes have led to increasing attention on inappropriate polypharmacy.

Deprescribing addresses the harms associated with inappropriate polypharmacy. It is a patientcentred process involving the discontinuation of one or more drugs that are potentially harmful or no longer required. ${ }^{4}$

\section{Is deprescribing safe?}

Many drugs are indicated to delay mortality so prescribers may be reluctant to discontinue them. Despite this concern, a systematic review of deprescribing found no change in mortality overall in randomised studies (odds ratio (OR) 0.82, 95\% confidence interval (Cl) 0.61-1.11). ${ }^{5}$ However, mortality was significantly decreased in non-randomised studies (OR 0.32, 95\% Cl 0.17-0.60)..$^{5}$ The review also found that patient-specific interventions significantly reduced mortality in randomised studies, but generalised educational interventions aimed at upskilling practitioners to alter prescribing behaviour did not change mortality. This evidence indicates that reducing polypharmacy may be achieved without perceivable adverse impacts on mortality and with clinically important benefits for some patients. Other reviews have investigated the impact of deprescribing in specific drug classes and specific settings (such as aged-care facilities and hospitals). This research generally suggested that deprescribing is safe (Table 1). ${ }^{5-11}$

\section{What are some prompts to consider deprescribing?}

Medicines should be reviewed regularly to ensure that each drug is effective for that individual and therapy remains consistent with their care goals. Treatment should also be underpinned by a current and valid diagnosis. ${ }^{12}$ A significant event like a fall, or an admission to hospital or a residential care facility, should prompt a thorough medicine review. ${ }^{12} \mathrm{~A}$ review should also be triggered by increasing frailty or a decline in either their cognitive function or ability to manage activities of daily living. ${ }^{12}$

\section{Falls}

Older people are at a significantly increased risk of falls. This is exacerbated by both polypharmacy and certain drugs such as psychotropics, cardiovascular drugs and anticholinergics. ${ }^{1,13}$ A New Zealand study found that deprescribing sedative and anticholinergic drugs significantly reduced the number of falls each person experienced..$^{14}$ Providing older people with written information supporting discontinuation has been shown to be an effective strategy to improve sedative discontinuation. ${ }^{15}$ Although our systematic review suggested that deprescribing does not alter the risk of having a first fall, it reduces the number of 
subsequent falls for an older person who has already fallen. ${ }^{5}$ Another review found that deprescribing interventions based on a medicine review resulted in a relative risk reduction of $24 \%(\mathrm{OR} 0.76,95 \% \mathrm{Cl}$ $0.62-0.93)^{7}$ in the number of people who fell.

\section{Adverse effects}

Older people are more susceptible to adverse effects due to increased frailty, poor homeostatic reserve and age-related changes in pharmacokinetics and pharmacodynamics. ${ }^{16}$ It can be a challenge to detect adverse effects in older people, particularly in those with cognitive impairment who may not be able to articulate their concerns. It is not uncommon for an adverse effect to be identified as a new symptom or condition, which can lead to a prescribing cascade (see an example in the Box). In this example, the prescribers did not consider the possibility of an adverse effect when evaluating the new symptoms. The cascade has been described in a study that found that older people who are prescribed cholinesterase inhibitors are at increased risk of subsequently being prescribed an anticholinergic drug (adjusted hazard ratio $1.55,95 \% \mathrm{Cl} 1.39-1.72) .^{17}$ The cascade could also occur in the alternate order - a new anticholinergic drug could contribute to confusion or delirium. If this is misdiagnosed as dementia, it could result in the prescription of a cholinesterase inhibitor.

The prevalence of polypharmacy in older people increases the likelihood that more than one drug contributes to the same adverse effect (e.g. oxycodone and oxybutynin both resulting in constipation and dry mouth).

\section{End-stage diseases}

In older people with a severe life-limiting condition, such as advanced dementia or end-stage organ failure, the potential benefit of preventive medicines may not be realised due to the person's short life expectancy and may not be the goal of their treatment. For example, 2-5 years of statin use is generally required to reduce the risk of stroke or myocardial infarction. ${ }^{18}$

\section{Box Example of a prescribing cascade}

An 85-year-old female was admitted to hospital with a hip fracture. She had fallen at home while changing her bedsheets after an episode of urinary incontinence, which she reported had worsened over the last few weeks. She had recently commenced donepezil for the management of Alzheimer's disease. In hospital, she was prescribed oxybutynin to treat the incontinence.

Prescribing oxybutynin to manage the adverse effects of the donepezil is an example of a prescribing cascade.
Managing preventive medicines can be challenging in the context of life-limiting illness or frailty. For example, although at least $15 \%$ of older Australians live with diabetes, ${ }^{19}$ little evidence is available on the effects of discontinuing drugs for diabetes. A recent review identified only two low-quality controlled studies of deprescribing these drugs." Tight glycaemic control (glycated haemoglobin $(\mathrm{HbAlc})<7 \%)$ may be appropriate in those who have sufficient life expectancy to benefit from the reduced risk of microvascular complications. However, for frail older people, intensive therapy increases the risk of hypoglycaemia without a mortality benefit. De-intensification of therapy is therefore often appropriate. ${ }^{20}$ In both studies, there was no significant difference in $\mathrm{HbAlc}$ between the group that discontinued diabetes drugs and those that continued."

\section{Approaches to safe deprescribing}

Drugs may sometimes be discontinued in older people with limited or no adverse effects. ${ }^{5}$ In other cases, the symptoms of the underlying condition may reappear or withdrawal effects may occur. A review did not find significant harms when antihypertensives, benzodiazepines and psychotropics were discontinued in older people. ${ }^{21}$

The risk of harm can be mitigated by gradually tapering medicines and carefully monitoring for withdrawal effects. It is often not possible to tell if a condition is a current problem while symptomrelieving drugs are used (e.g. proton pump inhibitors to manage reflux, or analgesics to manage pain). For these drugs, discontinuation should be trialled rather than considered definitive. If symptoms recur, restarting the medicine at a lower dose may be sufficient to manage this. ${ }^{21}$

\section{Reappearance of the original disease or symptoms}

Many older people are prescribed antihypertensives to reduce their risk of cardiovascular events. This needs to be carefully balanced with the potential for harms (e.g. dizziness, falls). ${ }^{22} \mathrm{~A}$ study of frail older people found that deprescribing antihypertensives resulted in an immediate increase in blood pressure, although this reverted to baseline within nine months. ${ }^{23}$ Another study found that systolic blood pressure increased by $7 \mathrm{mmHg}(95 \% \mathrm{Cl} 3-12)$ after discontinuing antihypertensives. ${ }^{24}$ Blood pressure should be routinely monitored during the first year after deprescribing to identify increases that may occur. ${ }^{22}$

For symptom management, proton pump inhibitors are recommended for 2-8 weeks, yet they are 
Table 1 Summary of systematic reviews of deprescribing

Continued over page

\begin{tabular}{|c|c|c|c|c|}
\hline \multirow[t]{2}{*}{ Study } & \multicolumn{4}{|c|}{ Participants } \\
\hline & Number & Age (years)* & Female (\%) & Inclusion criteria \\
\hline $\begin{array}{l}\text { Shrestha et al } \\
2019^{6}\end{array}$ & 1375 & Mean age $74.1-86.1$ & 57.6 & $\begin{array}{l}\text { Life-limiting illness and } \\
\text { limited life expectancy }\end{array}$ \\
\hline Kua et al $2019^{7}$ & 18,408 & $\begin{array}{l}83 \% \text { of studies had } \\
\text { mean age } 80-89\end{array}$ & 69.4 & $\begin{array}{l}\text { Terminally ill or palliative } \\
\text { care residents not } \\
\text { included }\end{array}$ \\
\hline
\end{tabular}

\section{Deprescribing} intervention

Hospital or Deprescribing

RACF medicine(s) or deprescribing as part of medicine optimisation

DACF Deprescribing
included

$\begin{array}{lllll}\begin{array}{l}\text { Thillainadesan } \\ \text { et al } 2018^{8}\end{array} & 2522 & \begin{array}{l}\text { Mean or median } \\ \text { age } 74.5-86.7\end{array} & \text { Not reported } & \text { Hospitalised older people Hospital }\end{array}$
et al $2018^{8}$ age $74.5-86.7$ polypharmacy and deprescribing individual targets

Deprescribing to reduce potentially inappropriate medicines

Page et al $2016^{5} \quad 34,143 \quad 73.8 \pm 5.4 \quad 48.2$

48.2

One or more medicines

Hospital,
RACF,
community

Deprescribing polypharmacy and community deprescribing individual targets

\begin{tabular}{|c|c|c|c|c|c|c|}
\hline $\begin{array}{l}\text { Johansson et al } \\
2016^{9}\end{array}$ & 10,980 & Mean age 69.7-87.7 & 0 to $80 \%$ & $\begin{array}{l}\text { Polypharmacy } \\
\text { ( } \geq 4 \text { medicines) }\end{array}$ & $\begin{array}{l}\text { Hospital, } \\
\text { RACF, } \\
\text { community }\end{array}$ & $\begin{array}{l}\text { Strategies to reduce } \\
\text { polypharmacy }\end{array}$ \\
\hline $\begin{array}{l}\text { Boghossian et al } \\
2017^{10}\end{array}$ & 1758 & $\begin{array}{l}\text { 48-57, except one } \\
\text { trial with mean age } 73\end{array}$ & Not reported & $\begin{array}{l}\text { PPI use for at least } \\
1 \text { month }\end{array}$ & Community & Deprescribing PPIs \\
\hline \multirow[t]{2}{*}{ Black et al $2017^{11}$} & \multirow[t]{2}{*}{6352} & \multirow[t]{2}{*}{ Mean age 77-84 } & \multirow[t]{2}{*}{0.5 to $58 \%$} & $\begin{array}{l}\text { Glyburide, serum } \\
\text { creatinine } \geq 176 \text { micromol/L }\end{array}$ & \multirow[t]{2}{*}{$\begin{array}{l}\text { RACF, } \\
\text { community }\end{array}$} & \multirow[t]{2}{*}{$\begin{array}{l}\text { Deprescribing } \\
\text { antihyperglycaemics }\end{array}$} \\
\hline & & & & $\begin{array}{l}\text { HbAlc } \leq 6 \% \text {, on any } \\
\text { diabetes medicine }\end{array}$ & & \\
\hline
\end{tabular}

\begin{tabular}{|c|c|c|c|c|c|}
\hline $\mathrm{Cl}$ & confidence interval & OR & odds ratio & RCT & randomised controlled tria \\
\hline$E Q-5 D$ & EuroQol-5D & PPI & proton pump inhibitor & $\mathrm{RR}$ & risk ratio \\
\hline $\mathrm{HbA1C}$ & glycated haemoglobin & QOL & quality of life & SD & standard deviation \\
\hline N/A & not applicable & RACF & residential aged-care facility & & \\
\hline
\end{tabular}

An $A 3$ single-page version of this table is available online.

commonly continued for prolonged periods. ${ }^{10}$ Stopping them may result in rebound hyperacidity, or lack of symptom control, ${ }^{10}$ especially during the first two weeks. A study that deprescribed proton pump inhibitors during hospital admissions found that $57 \%$ were still discontinued after three months. ${ }^{25}$ Tapering the dose may reduce the risk of rebound symptoms, particularly if the initial dose is high. Proton pump inhibitors, $\mathrm{H}_{2}$ antagonists or antacids (e.g. Mylanta) can be used as needed to relieve rebound symptoms.

The fracture risk in people with osteoporosis may be reduced using denosumab or bisphosphonates. Bisphosphonates can be discontinued after 3-6 years in many people without altering fracture risk. ${ }^{5,26}$ For example, a six-year study of zoledronic acid suggested treatment could be stopped after six annual infusions, with treatment effects maintained for at least three years. ${ }^{26}$ Unlike bisphosphonates, denosumab is not incorporated into the bone matrix so the effect on bone resorption is not maintained after treatment is discontinued. Discontinuing denosumab therefore results in rapid bone loss and the fracture risk reverts to baseline levels. ${ }^{27,28}$ Periodic monitoring may identify changes in bone mineral density after a bisphosphonate has been discontinued.

\section{Withdrawal symptoms}

Discontinuing drugs can result in withdrawal symptoms. People taking long-term benzodiazepines are likely to be physiologically dependent.

A withdrawal syndrome can include anxiety, 
Table 1 Summary of systematic reviews of deprescribing (continued)

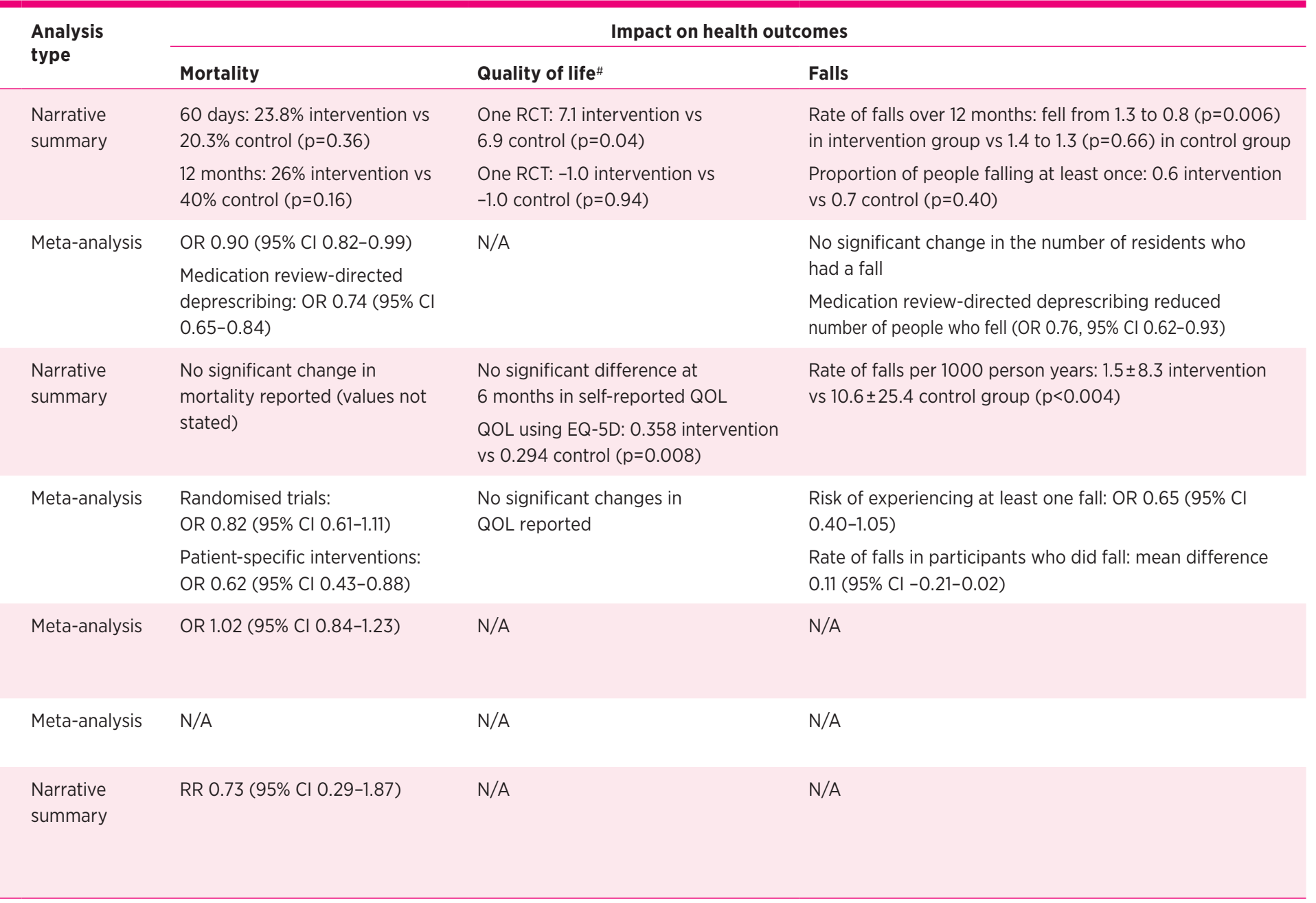

* Reported as mean \pm SD unless otherwise stated

\# Higher scores represent increased quality of life

$\mathrm{Cl}$ confidence interval

EQ-5D Euro-Qol-5D

HbA1C glycated haemoglobin

N/A not applicable

$\begin{array}{ll}\text { OR } & \text { odds ratio } \\ \text { PPI } & \text { proton pump inhibitor } \\ \text { QOL } & \text { quality of life } \\ \text { RACF } & \text { residential aged-care facility }\end{array}$

$\mathrm{RCT}$ randomised controlled trial

$\mathrm{RR} \quad$ risk ratio

SD standard deviation

An A3 single-page version of this table is available online.

irritability, insomnia and myoclonic jerks. One study demonstrated that $38 \%$ of people reported withdrawal symptoms when discontinuing benzodiazepines and Z-drugs (zopiclone and zolpidem) ${ }^{29}$ This highlights the importance of slowly tapering medicines to minimise withdrawal symptoms. ${ }^{30}$ This also increases the likelihood of the medicine being successfully deprescribed.

\section{Enablers and barriers to deprescribing for patients}

It is important to involve patients and their carers in the decision to discontinue medicines when possible. ${ }^{4}$ Most older people are willing to stop one or more drugs if their doctor says they can. ${ }^{31} \mathrm{~A}$ person may be reluctant to do this if they believe a drug is still necessary or that they may derive future benefit from it. ${ }^{32}$ Patients may be concerned about relapse or withdrawal symptoms, ${ }^{32}$ but are more willing to have a medicine deprescribed if they know they can restart it if required. ${ }^{33}$ Inadequate time with the prescriber to discuss discontinuation, and lack of guidance on how to stop a medicine (e.g. is tapering needed, what monitoring and follow-up will occur), is another barrier. ${ }^{32}$ This highlights the importance of providing additional information about the risks and benefits of medicine use to facilitate an older person's willingness to deprescribe. For example, those who received a brochure that described harms from Z-drugs and suggested alternative options were significantly more likely to discontinue the medicine than those who received usual care. ${ }^{15}$ 


\section{Tools to support deprescribing decisions}

There are many tools to assist clinicians to deprescribe medicines in older people. ${ }^{34}$ Implicit tools such as the deprescribing algorithm (Table 2 ) $35-38$ outline approaches for reviewing an older person's medicine list to identify targets for deprescribing. These tools require application by a health professional. Explicit tools provide criteria-based guidance on how to approach the deprescribing of specific drugs - an example of medicine-specific guidelines is shown in Table 3.

Referring an older person for a Home Medicines Review or a Residential Medication Management Review by a pharmacist can assist the process. The pharmacist can help to identify targets for deprescribing and develop a plan for tapering doses. Deprescribing advice from pharmacists has been shown to reduce inappropriate prescribing in older people. ${ }^{39}$ It is important to ensure that medicine changes are communicated with the older person's community pharmacist so they can assist in implementing the change. This is particularly important if the pharmacist prepares a dose administration aid for the older person.

After identifying deprescribing targets, it is necessary to consider the order in which to deprescribe medicines. Often it is useful to deprescribe medicines with limited noticeable withdrawal effects first to reassure the person that the process is tolerable (Table 4). ${ }^{35,37,40-45}$ It is usually advisable to limit deprescribing to just 1-3 medicines at a time. However, it is important to make sure they do not have overlapping indications so it is clear which medicine is responsible if withdrawal effects occur. ${ }^{35}$

\section{Table 2 Examples of medicine decisions using the deprescribing algorithm}

\section{Criteria \\ 1. Is the medicine inappropriately prescribed? \\ 2. Is the medicine having any adverse effects or interactions? \\ 3. Is the medicine intended for symptom relief and symptoms are stable or resolved?}

4. Is the medicine intended to prevent future events?

\section{Examples}

Empagliflozin in renal impairment

Laxatives in patients with diarrhoea

Mineral supplements in patients with no documented deficiency

Symptomatic postural hypotension in a patient taking multiple antihypertensives discontinuing antihypertensive drugs in older people with orthostatic hypotension increases the probability of recovery. ${ }^{36}$

Inhaled corticosteroid in a patient with stable chronic obstructive pulmonary disease - a 'reallife' study observed that withdrawal of inhaled corticosteroids is possible with no increased risk of exacerbations in patients with stable chronic obstructive pulmonary disease. ${ }^{37}$

Prolonged dual antiplatelet therapy after percutaneous coronary intervention - continuing clopidogrel-based dual antiplatelet therapy beyond six months after percutaneous coronary intervention in older people increases bleeding risk without significantly preventing ischaemic events. ${ }^{38}$

Source: reference 35

Table 3 Tools to support deprescribing decisions

\begin{tabular}{|c|c|c|}
\hline Link & Organisation & Description \\
\hline $\begin{array}{l}\text { www.primaryhealthtas.com.au/resources/ } \\
\text { deprescribing-resources }\end{array}$ & Primary Health Tasmania & $\begin{array}{l}\text { Deprescribing guidelines for commonly used medicines } \\
\text { (e.g. benzodiazepines, aspirin, statins) }\end{array}$ \\
\hline http://www.match-d.com.au & $\begin{array}{l}\text { WA Centre for Health and Ageing, } \\
\text { University of Western Australia }\end{array}$ & $\begin{array}{l}\text { Medication appropriateness tool for comorbid health } \\
\text { conditions in dementia }\end{array}$ \\
\hline \multirow[t]{2}{*}{ http://www.nswtag.org.au/deprescribing-tools } & NSW Therapeutic Advisory Group & $\begin{array}{l}\text { Deprescribing guidelines for commonly used medicines in } \\
\text { older adults (e.g. proton pump inhibitors, long-term opioid } \\
\text { analgesics) }\end{array}$ \\
\hline & & Deprescribing consumer information leaflets \\
\hline \multirow[t]{2}{*}{ https://deprescribing.org/resources } & Bruyère Research Institute & $\begin{array}{l}\text { Deprescribing guidelines and algorithms for commonly used } \\
\text { medicines (e.g. antihyperglycaemics) }\end{array}$ \\
\hline & & Deprescribing information pamphlets for consumers \\
\hline
\end{tabular}


Table 4 Risk of adverse drug withdrawal events for common target medicines in older people

\begin{tabular}{|c|c|c|c|}
\hline \multicolumn{3}{|c|}{ Reason for considering discontinuation of the drug } & \multirow{2}{*}{$\begin{array}{l}\text { Risk of withdrawal } \\
\text { event or symptom } \\
\text { recurrence }\end{array}$} \\
\hline Inappropriate medicines & $\begin{array}{l}\text { No symptomatic benefit from } \\
\text { continued therapy }\end{array}$ & $\begin{array}{l}\text { Possible symptomatic benefit from } \\
\text { continued therapy }\end{array}$ & \\
\hline $\begin{array}{l}\text { Benzodiazepines, antipsychotics, tricyclic } \\
\text { antidepressants, long-acting sulfonylureas, } \\
\text { non-steroidal anti-inflammatory drugs, } \\
\text { stimulant laxatives }\end{array}$ & Antihypertensives & $\begin{array}{l}\text { Analgesics, inhaled, topical or oral } \\
\text { corticosteroids, diuretics, antiemetics, } \\
\text { oral and topical oestrogens, anti-reflux } \\
\text { drugs, anxiolytics, hypnotics, levodopa, } \\
\text { nasal decongestants, nitrates }\end{array}$ & $\begin{array}{l}\text { Likely - taper dose } \\
\text { before stopping }\end{array}$ \\
\hline $\begin{array}{l}\text { Antispasmodics, anticholinergic } \\
\text { antihistamines, short-acting calcium channel } \\
\text { blockers, muscle relaxants, dipyridamole, } \\
\text { nitrofurantoin, oxybutinin, amiodarone }\end{array}$ & $\begin{array}{l}\text { Statins, potassium supplements, } \\
\text { mineral supplements, vitamins, } \\
\text { bisphosphonates, other } \\
\text { antidiabetic drugs, strontium }\end{array}$ & $\begin{array}{l}\text { Iron supplements, herbal remedies, cough } \\
\text { suppressants, digoxin, prophylactic } \\
\text { antibiotics, antiglaucoma drugs }\end{array}$ & $\begin{array}{l}\text { Less likely - stop } \\
\text { drug without dose } \\
\text { tapering }\end{array}$ \\
\hline
\end{tabular}

Source: references $38-45$

\section{Conclusion}

In the deprescribing process, the potential benefits and risks of continuing and discontinuing medicines are considered for the individual. Deprescribing to reduce polypharmacy can be achieved with potential benefits for mortality, quality of life and cognition. While some medicines can be deprescribed without noticeable effects, others are associated with predictable drug withdrawal symptoms. These medicines require more careful deliberation, tapering and monitoring if they are to be discontinued. Deprescribing medicines that are no longer indicated reduces the risk of drug-related harm and is an essential part of the quality use of medicines. $\varangle$

\section{Conflict of interest: none declared}

Acknowledgement: Kathleen Potter drafted Table 4 in collaboration with Christopher Etherton-Beer.

\section{REFERENCES}

1. Gnjidic D, Hilmer SN, Blyth FM, Naganathan V, Waite L, Seibel MJ, et al. Polypharmacy cutoff and outcomes: five or more medicines were used to identify community-dwelling older men at risk of different adverse outcomes. J Clin Epidemiol 2012;65:989-95. https://doi.org/10.1016/ j.jclinepi.2012.02.018

2. Vanderman AJ, Moss JM, Bryan WE 3rd, Sloane R, Jackson GL, Hastings SN. Evaluating the impact of medication safety alerts on prescribing of potentially inappropriate medications for older veterans in an ambulatory care setting. J Pharm Pract 2017;30:82-8 https://doi.org/10.1177/0897190015621803

3. Page AT, Falster MO, Litchfield M, Pearson SA Etherton-Beer C. Polypharmacy among older Australians, 2006-2017: a population-based study. Med J Aust 2019;211:71-5. https://doi.org/10.5694/mja2.50244

4. Page A, Clifford R, Potter K, Etherton-Beer C. A concept analysis of deprescribing medications in older people. J Pharm Pract Res 2018;48:132-48. https://doi.org/10.1002/ jppr.1361

5. Page AT, Clifford RM, Potter K, Schwartz D, Etherton-Beer CD. The feasibility and effect of deprescribing in older adults on mortality and health: a systematic review and meta-analysis. Br J Clin Pharmacol 2016;82:583-623. https://doi.org/10.1111/bcp.12975

6. Shrestha S, Poudel A, Steadman K, Nissen L. Outcomes of deprescribing interventions in older patients with life-limiting illness and limited life expectancy: a systematic review. Br J Clin Pharmacol 2019 Sep 4 [Epub ahead of print]. https://doi.org/10.1111/bcp.14113

7. Kua CH, Mak VS, Huey Lee SW. Health outcomes of deprescribing interventions among older residents in nursing homes: a systematic review and meta-analysis. J Am Med Dir Assoc 2019;20:362-372.e11. https://doi.org/ 10.1016/j.jamda.2018.10.026

8. Thillainadesan J, Gnjidic D, Green S, Hilmer SN. Impact of deprescribing interventions in older hospitalised patients on prescribing and clinical outcomes: a systematic review of randomised trials. Drugs Aging 2018;35:303-19. https://doi.org/10.1007/s40266-018-0536-4

9. Johansson T, Abuzahra ME, Keller S, Mann E, Faller B, Sommerauer $\mathrm{C}$, et al. Impact of strategies to reduce polypharmacy on clinically relevant endpoints: a systematic review and meta-analysis. Br J Clin Pharmacol 2016;82:532-48. https://doi.org/10.1111/bcp.12959

10. Boghossian TA, Rashid FJ, Thompson W, Welch V, Moayyedi P, Rojas-Fernandez C, et al. Deprescribing versus continuation of chronic proton pump inhibitor use in adults. Cochrane Database Syst Rev 2017;3:CD011969. https://doi.org/10.1002/14651858.CD011969.pub2

11. Black CD, Thompson W, Welch V, McCarthy L Rojas-Fernandez C, Lochnan H, et al. Lack of evidence to guide deprescribing of antihyperglycemics: a systematic review. Diabetes Ther 2017;8:23-31. https://doi.org/10.1007/ s13300-016-0220-9

12. Page AT, Potter K, Clifford R, McLachlan AJ, Etherton-Beer C Medication appropriateness tool for co-morbid health conditions in dementia: consensus recommendations from a multidisciplinary expert panel. Intern Med J 2016;46:1189-97. https://doi.org/10.1111/imj.13215

13. Woolcott JC, Richardson KJ, Wiens MO, Patel B, Marin J, Khan KM, et al. Meta-analysis of the impact of 9 medication classes on falls in elderly persons. Arch Intern Med 2009;169:1952-60. https://doi.org/10.1001/ archinternmed.2009.357

14. Ailabouni N, Mangin D, Nishtala PS. DEFEAT-polypharmacy: deprescribing anticholinergic and sedative medicines feasibility trial in residential aged care facilities. Int J Clin Pharm 2019;41:167-78. https://doi.org/10.1007/ s11096-019-00784-9 
15. Kuntz JL, Kouch L, Christian D, Hu W, Peterson PL. Patient education and pharmacist consultation influence on nonbenzodiazepine sedative medication deprescribing success for older adults. Perm J 2019;23:18-161. https://doi.org/10.7812/TPP/18-161

16. Hilmer SN. ADME-tox issues for the elderly Expert Opin Drug Metab Toxicol 2008;4:1321-31. https://doi.org/10.1517/17425255.4.10.1321

17. Gill SS, Mamdani M, Naglie G, Streiner DL, Bronskill SE, Kopp A, et al. A prescribing cascade involving cholinesterase inhibitors and anticholinergic drugs. Arch Intern Med 2005;165:808-13. https://doi.org/10.1001/archinte.165.7.808

18. Holmes HM, Min LC, Yee M, Varadhan R, Basran J, Dale W, et al. Rationalizing prescribing for older patients with multimorbidity: considering time to benefit. Drugs Aging 2013;30:655-66. https://doi.org/10.1007/s40266-013-0095-7

19. Australian Institute of Health and Welfare. Diabetes [Internet]. Canberra: AlHW; 2019. https://www.aihw.gov.au/ reports/diabetes/diabetes/data [cited 2020 Aug 1]

20. Primary Health Tasmania. A guide to deprescribing antihyperglycaemic agents [Internet]. Hobart: Primary Health Tasmania; 2019. https://www.primaryhealthtas.com.au/ resources/deprescribing-resources [cited 2020 Aug 1]

21. Iyer S, Naganathan V, McLachlan AJ, Le Couteur DG. Medication withdrawal trials in people aged 65 years and older: a systematic review. Drugs Aging 2008;25:1021-31. https://doi.org/10.2165/0002512-200825120-00004

22. Parekh N, Page A, Ali K, Davies K, Rajkumar C. A practica approach to the pharmacological management of hypertension in older people. Ther Adv Drug Saf 2017:8:117-32. https://doi.org/10.1177/2042098616682721

23. Gulla C, Flo E, Kjome RL, Husebo BS. Deprescribing antihypertensive treatment in nursing home patients and the effect on blood pressure. J Geriatr Cardiol 2018;15:275-83. https://doi.org/10.11909/j.issn.1671-5411.2018.04.011

24. Moonen JE, Foster-Dingley JC, de Ruijter W, van der Grond J, Bertens AS, van Buchem MA, et al. Effect of discontinuation of antihypertensive treatment in elderly people on cognitive functioning - the DANTE Study Leiden: a randomized clinical trial. JAMA Intern Med 2015:175:1622-30. https://doi.org/10.1001/jamainternmed.2015.4103

25. Wahking RA, Steele RL, Hanners RE, Lockwood SM, Davis KW. Outcomes from a pharmacist-led proton pump inhibitor stewardship program at a single institution. Hosp Pharm 2018:53:59-67. https://doi.org/10.1177/0018578717747192

26. Black DM, Reid IR, Cauley JA, Cosman F, Leung PC, Lakatos $P$, et al. The effect of 6 versus 9 years of zoledronic acid treatment in osteoporosis: a randomized second extension to the HORIZON-Pivotal Fracture Trial (PFT). J Bone Miner Res 2015;30:934-44. https://doi.org/10.1002/ jbmr.2442

27. Cummings SR, Ferrari S, Eastell R, Gilchrist N, Jensen JB, McClung $\mathrm{M}$, et al. Vertebral fractures after discontinuation of denosumab: a post hoc analysis of the randomized placebo-controlled FREEDOM trial and its extension. J Bone Miner Res 2018;33:190-8. https://doi.org/10.1002/ jbmr.3337

28. Zanchetta MB, Boailchuk J, Massari F, Silveira F, Bogado C, Zanchetta JR. Significant bone loss after stopping long term denosumab treatment: a post FREEDOM study. Osteoporos Int 2018;29:41-7. https://doi.org/10.1007/ s00198-017-4242-6

29. Martin P, Tamblyn R, Benedetti A, Ahmed S, Tannenbaum C. Effect of a pharmacist-led educational intervention on inappropriate medication prescriptions in older adults: the D-PRESCRIBE randomized clinical trial. JAMA 2018:320:1889-98. https://doi.org/10.1001/jama.2018.16131

30. NPS MedicineWise. Managing benzodiazepine dependence in primary care [Internet]. Sydney: NPS MedicineWise; 2015. www.nps.org.au/news/managing-benzodiazepinedependence-in-primary-care [cited 2020 Aug 1]
31. Reeve E, Wiese MD, Hendrix I, Roberts MS, Shakib S. People's attitudes, beliefs, and experiences regarding polypharmacy and willingness to deprescribe. J Am Geriatr Soc 2013;61:1508-14. https://doi.org/10.1111/jgs.12418

32. Reeve E, To J, Hendrix I, Shakib S, Roberts MS, Wiese MD. Patient barriers to and enablers of deprescribing: a systematic review. Drugs Aging 2013;30:793-807. https://doi.org/10.1007/s40266-013-0106-8

33. Reeve E, Low LF, Hilmer SN. Beliefs and attitudes of older adults and carers about deprescribing of medications: a qualitative focus group study. Br J Gen Pract 2016;66:e552-60. https://doi.org/10.3399/bjgp16X685669

34. Thompson W, Lundby C, Graabaek T, Nielsen DS, Ryg J, Søndergaard J, et al. Tools for deprescribing in frail older persons and those with limited life expectancy: a systematic review. J Am Geriatr Soc 2019;67:172-80. https://doi.org/ 10.1111/jgs.15616

35. Potter K, Page A, Clifford R, Etherton-Beer C. Deprescribing: a guide for medication reviews. J Pharm Pract Res 2016;46:358-67. https://doi.org/10.1002/jppr.1298

36. Moonen JE, Foster-Dingley JC, de Ruijter W, van der Grond J, de Craen AJ, van der Mast RC. Effect of discontinuation of antihypertensive medication on orthostatic hypotension in older persons with mild cognitive impairment: the DANTE Study Leiden. Age Ageing 2016;45:249-55. https://doi.org/ 10.1093/ageing/afv199

37. Vogelmeier C, Worth H, Buhl R, Criée CP, Lossi NS, Mailänder C, et al. "Real-life" inhaled corticosteroid withdrawal in COPD: a subgroup analysis of DACCORD. Int J Chron Obstruct Pulmon Dis 2017;12:487-94. https://doi.org/10.2147/COPD.S125616

38. Piccolo R, Magnani G, Ariotti S, Gargiulo G, Marino M, Santucci A, et al. Ischaemic and bleeding outcomes in elderly patients undergoing a prolonged versus shortened duration of dual antiplatelet therapy after percutaneous coronary intervention: insights from the PRODIGY randomised trial. Eurolntervention 2017:13:78-86. https://doi.org/10.4244/EIJ-D-16-00497

39. Scott IA, Anderson K, Freeman CR, Stowasser DA. First do no harm: a real need to deprescribe in older patients. Med J Aust 2014;201:390-2. https://doi.org/10.5694/ mja14.00146

40. Garfinkel D, Zur-Gil S, Ben-Israel J. The war against polypharmacy: a new cost-effective geriatric-palliative approach for improving drug therapy in disabled elderly people. Isr Med Assoc J 2007;9:430-4

41. Fick DM, Cooper JW, Wade WE, Waller JL, Maclean JR, Beers $\mathrm{MH}$. Updating the Beers criteria for potentially inappropriate medication use in older adults: results of a US consensus panel of experts. Arch Intern Med 2003;163:2716-24. https://doi.org/10.1001/archinte.163.22.2716

42. Laroche ML, Charmes JP, Merle L. Potentially inappropriate medications in the elderly: a French consensus panel list. Eur J Clin Pharmacol 2007;63:725-31. https://doi.org/10.1007/ s00228-007-0324-2

43. Basger BJ, Chen TF, Moles RJ. Inappropriate medication use and prescribing indicators in elderly Australians: development of a prescribing indicators tool. Drugs Aging 2008;25:777-93. https://doi.org/10.2165/00002512-200825090-00004

44. Woodward MC. Deprescribing: achieving better health outcomes for older people through reducing medications. J Pharm Pract Res 2003;33:323-8. https://doi.org/10.1002/ ppr2003334323

45. Holt S, Schmiedl S, Thürmann PA. Potentially inappropriate medications in the elderly: the PRISCUS list. Dtsch Arztebl Int 2010;107:543-51. https://doi.org/10.3238/ arztebl.2010.0543 